\title{
Induction of cellular immunity in a parathyroid carcinoma treated with tumor lysate-pulsed dendritic cells
}

\author{
Matthias Schott ${ }^{1}$, Joachim Feldkamp ${ }^{1}$, Dirk Schattenberg ${ }^{3}$, Thilo Krueger ${ }^{3}$, Cornelia Dotzenrath ${ }^{2}$, \\ Jochen Seissler ${ }^{3}$ and Werner A Scherbaum ${ }^{1,3}$ \\ Departments of ${ }^{1}$ Endocrinology, ${ }^{2}$ Surgery, and ${ }^{3}$ German Diabetes Research Institute, Heinrich Heine University, Duesseldorf, Moorenstr. 5, \\ 40225 Duesseldorf, Germany \\ (Correspondence should be addressed to M Schott, Department of Endocrinology; Email: schottmt@uni-duesseldorf.de)
}

\begin{abstract}
Background: Cytotoxic T-lymphocyte-mediated tumor immunity against major histocompatibility antigen class II-negative tumors requires help from $\mathrm{CD} 4^{+}$T-cells. The major antigen presenting cells for $\mathrm{CD} 4^{+}$cell activation are dendritic cells. Studies in mice and humans have demonstrated the potent capacity of these cells to induce specific antitumor immunity.

Objective: To control the growth of a metastasized parathyroid carcinoma, by immunizing a patient with tumor lysate and parathyroid hormone-pulsed dendritic cells.

Design and Methods: Mature dendritic cells were generated from peripheral blood monocytes in the presence of granulocyte/macrophage colony-stimulating factor, interleukin-4 and tumor necrosis factor $\alpha$. Antigen-loaded dendritic cells were delivered by subcutaneous and intralymphatical injections. After five cycles, we added keyhole limpet hemocyanin (KLH) as a $\mathrm{CD}^{+}$helper antigen.

Results: After 10 vaccinations, a specific cellular immune response to tumor lysate was observed. In vitro T-cell proliferation assays revealed a dose-dependent stimulation index of 1.8-5.7 compared with 0.9-1.1 before vaccination. In vivo immune response was demonstrated by positive delayed-type hypersensitivity toward tumor lysate. Intradermal injection of tumor lysate resulted in an erythema and induration, suggesting the efficient generation of tumor lysate-specific memory T-cells.

Conclusions: These data indicate that dendritic cell vaccination can induce in vitro and in vivo responses in a highly malignant endocrine carcinoma. Regardless of the clinical outcome of our patient, this approach might be generally applicable to other advanced, radio- and chemotherapy-resistant endocrine malignancies, such as adrenal carcinomas and metastasized medullary and anaplastic thyroid carcinomas.
\end{abstract}

European Journal of Endocrinology 142 300-306

\section{Introduction}

The underlying mechanism leading to humoral and cellular antitumor immunity in humans remains poorly understood. Models for immune-mediated tumor regression in mice have defined an essential role for $\mathrm{CD}^{+}$cytotoxic T-lymphocytes (CTLs) requiring help from $\mathrm{CD} 4^{+} \mathrm{T}$-cells $(1,2)$. As most tumors do not express major histocompatibility complex (MHC) class II antigens, priming of $\mathrm{CD}^{+}{ }^{+} \mathrm{T}$-cells by $\mathrm{MHC}$ class $\mathrm{II}^{+}$antigenpresenting cells (APCs) presenting antigen to the $\mathrm{CD} 4^{+}$ cells is the initial event for the induction of antitumor immunity. Activation of CTLs by MHC class I restricted antigens may have a role in this process $(3,4)$. MHC class II+ APCs can be macrophages, dendritic cells and B-cells, although the last of these seem to be limited in their ability to function as primary APCs or even inhibit induction of T-cell-dependent tumor immunity $(5,6)$. Compelling evidence suggests that dendritic cells are the main cells specialized in presenting antigens to naive T-cells (7). Compared with other APCs, MHCpeptide complexes are expressed to a 10-100-fold greater extent on dendritic cells (8). Dendritic cells also express many accessory molecules that interact with receptors on T-cells such as cluster of differentiation (CD)80/B7-1, CD86/B7-2, CD58/lymphocyte function associated antigen (LFA)-3/, and CD54/intercellular adhesion molecule (ICAM)-1 $(9,10)$. Consistent with the idea of unique antigen presentation, several studies have documented the exceptional ability of dendritic cells to stimulate naive $\mathrm{CD} 4^{+}$and $\mathrm{CD} 8^{+}$T-cells in vitro and in vivo (11).

Immunization with tumor antigen-loaded dendritic cells may, therefore, represent a potentially powerful method of inducing antitumor immunity. Antigenspecific CTL responses have been demonstrated in several animal models with tumor regression or eradication, for example central nervous system tumors (12) 
and lung metastases of colon carcinoma (13). Using tumor lysate or a cocktail of peptides (known to be recognized by CTLs), an immune response with tumor eradication has been reported in metastasized melanomas in humans (14). Significant responses were evident in $31 \%$ of the patients. Using prostate-specific membrane antigen-loaded dendritic cells, nine of 33 patients with advanced prostate cancer responded to vaccination (US-National Prostate Cancer Project) (15).

In this paper, we will report on the vaccination of a patient with advanced parathyroid carcinoma with tumor lysate and parathyroid hormone (PTH) using dendritic cells for antigen delivery. Our clinical and immunological monitoring provide further insight into the powerful antigen-presenting capacity of dendritic cells for induction of a tumor-specific immune response. We will present strong evidence that, after 12 cycles of vaccination, the patient shows specific immune response to tumor lysate and keyhole limpet hemocyanin (KLH). Whether that response is effective for tumor eradication remains unknown. Further follow-up research is necessary to demonstrate clinical effectiveness and impact on the survival of the patient.

\section{Materials and methods}

\section{Patient}

The patient (a woman aged 50 years) was referred to our clinic in 1991. Primary hyperparathyroidism was diagnosed, and a parathyroid gland was excised and histologically classified as benign adenoma. After surgery, serum calcium and PTH concentrations initially decreased, but then steadily increased over the years of follow-up examination. In 1994 and 1995, the neck was re-explored and aberrant parathyroid tissue was excised from the left submandibular region, leading to the diagnosis of a parathyroid carcinoma. In the past 2 years, all symptoms of long-term hypercalcemia have appeared, with severe bone pain, profound weight loss and extreme muscle weakness. Using intravenous treatment with bisphosphonates, we were able to ameliorate the symptoms of hypercalcemia. In the summer of 1998 , the patient's serum PTH increased to $1080 \mathrm{pg} / \mathrm{ml}$ (normal range $<50 \mathrm{pg} / \mathrm{ml}$ ). Spiral-computed tomography scans revealed a local recurrence of carcinoma in the neck, and a lung metastasis in the lower right lobe. After re-exploration, with resection of the cervical recurrence and the lung metastasis, total serum PTH concentrations decreased markedly, but remained greater than normal values $(>200 \mathrm{pg} / \mathrm{ml})$, indicating residual carcinoma tissue. As the patient refused chemotherapy, we initiated an immunotherapy in an attempt to eradicate the tumor. The study procedure was approved by the Clinical Institutional Ethical Review Board. The patient gave her informed consent to undergo the procedure.

\section{Treatment}

Antigen-pulsed dendritic cells were administered simultaneously by subcutaneous (in $100 \mu \mathrm{l} 0.9 \%$ sterile sodium chloride), and intralymphatic (100 $\mu \mathrm{l})$ injections. Intralymphatic injections (guided by ultrasonography) were given into inguinal lymph nodes $(n=3)$ or in the perinodal area. To date, the patient has received 12 vaccinations. The first four treatments were administered weekly and the following vaccinations were continued at 2 -week intervals. KLH was introduced as a $\mathrm{CD}^{+}$helper antigen after the sixth immunization cycle.

\section{Generation of dendritic cells from peripheral blood}

Immature dendritic cells were generated with minor modifications as described elsewhere (16-18). Briefly, mononuclear cells were prepared from peripheral blood $(100 \mathrm{ml})$ using Ficoll-Hypaque density centrifugation. Peripheral blood mononuclear cells (PBMC) were resuspended in RPMI 1640 (Sigma) plus 10\% fetal calf serum (FCS) (Biochrom KG, Berlin, Germany) and were allowed to adhere to plastic dishes (Corning Costar, Bodenheim, Germany). After $2 \mathrm{~h}$ at $37^{\circ} \mathrm{C}$, non-adherent cells were removed, and the adherent cells were cultured for 7 days with GM-CSF $(800 \mathrm{U} / \mathrm{ml}$; PromoCell, Heidelberg, Germany) and interleukin (IL)-4 (500 U/ml; PromoCell). On day 3, cells were fed with GM-CSF $(800 \mathrm{U} / \mathrm{ml})$ and IL-4 $(500 \mathrm{U} / \mathrm{ml})$. After the third cycle we used, for vaccination, mature dendritic cells that were generated by addition of GM-CSF $(800 \mathrm{U} / \mathrm{ml})$ and tumour necrosis factor $\alpha(\mathrm{TNF} \alpha ; 1000 \mathrm{U} / \mathrm{ml}$, PromoCell) on day 6 for another $24 \mathrm{~h}$ of culture. Specific antigens (tumor lysate, PTH and KLH, each separately) were added. Phenotypic changes were assessed by flow cytometric analysis.

\section{Pulsing of dendritic cells generated in vitro}

After 6 days of culturing, $5 \times 10^{6}$ dendritic cells were pulsed with tumor lysate $\left(100 \mu \mathrm{g} / 1 \times 10^{6}\right.$ cells $/ \mathrm{ml}$ medium), PTH ( $1 \mu \mathrm{g} / \mathrm{ml}$; AS $1-84$, Sigma; after the sixth cycle) and KLH $(100 \mu \mathrm{g} / \mathrm{ml}$, after the sixth cycle) for $4 \mathrm{~h}$ at $37^{\circ} \mathrm{C}$. Antigen-loaded dendritic cells were washed three times in sterile $0.9 \%$ sodium chloride, and resuspended in $100 \mu \mathrm{l}$ before injection.

\section{Preparation of tumor lysate}

After resection, the local metastasis was immediately placed in PBS. Tissue was cut in small pieces, and tumor cells were dispersed in RPMI 1640 to create a single-cell suspension. Cells were lysed by repeated freezing and thawing, and by additional mechanical homogenizing using a conical homogenizer (Merck, Frankfurt, Germany). Larger particles were removed 
by centrifugation (10 min, 600 r.p.m.), supernatant was passed through a $0.2 \mu \mathrm{m}$ filter, protein concentration was determined, and aliquots were stored at $-80^{\circ} \mathrm{C}$ until required for use.

\section{Analysis of T-cell proliferative response}

Freshly prepared or cryopreserved PBMC were resuspended in RPMI 1640, 10\% autologous serum with penicillin $(100 \mathrm{U} / \mathrm{ml}) /$ streptomycin $(100 \mu \mathrm{g} / \mathrm{ml})$. Six replicates of $1 \times 10^{5}$ cells were cultured in roundbottom 96-well tissue culture plates (Corning) in the presence of tumor lysate $(1-100 \mu \mathrm{g} / \mathrm{ml})$, ovalbumin $(1-100 \mu \mathrm{g} / \mathrm{ml})$, PTH $(1 \mu \mathrm{g} / \mathrm{ml})$, phytohemagglutinin (PHA; $1-100 \mu \mathrm{g} / \mathrm{ml}$; Sigma) or KLH $(1-100 \mu \mathrm{g} / \mathrm{ml}$; Calbiochem, La Jolla, CA, USA) for 5 days. Cells were pulsed with $1 \mu \mathrm{Ci}\left[{ }^{3} \mathrm{H}\right]$ thymidine per well (Amersham, Aylesbury, Bucks, UK) $18 \mathrm{~h}$ before harvesting. Thymidine incorporation was assessed using a microscintillation counter (Packard, Meriden, CT, USA), and the mean value of each six replicate stimulations was determined. Cellular proliferation was expressed as the stimulation index (SI): mean counts per minute incorporated in the presence of antigen divided by the mean counts per minute incorporated in the presence of ovalbumin.

\section{Flow cytometric analysis (FACS)}

After 7 days of culture, dendritic cells were analyzed by FACS (Becton Dickinson) using the following monoclonal antibodies conjugated with fluorescein isothiocyanate (FITC) or phycoerythrin: anti-CD1a, antiCD80 (B7-1), anti-CD83, anti-CD86 (B7-2), anti-CD4, anti-CD8, anti-CD14, anti-CD19, anti-human leukocyte antigen (HLA) class I and anti-HLA class II (Coulter Immunotec, Hamburg, Germany). FITC-conjugated or phycoerythrin-conjugated isotype-matched antibodies were used as controls. Dead cells were gated out after staining with $0.5 \mu \mathrm{g} / \mathrm{ml}$ propidium iodide solution. In total, five individual dendritic cell preparations were tested.

\section{Delayed-type hypersensitivity (DTH)}

Delayed-type hypersensitivity skin tests were performed with tumor lysate ( $5 \mu \mathrm{g}$ in $50 \mu \mathrm{l} 0.9 \%$ sodium chloride) and PTH $(1 \mu \mathrm{g})$ at the beginning and after the second, fourth, sixth, eighth and tenth immunizations. After the sixth cycle, KLH $(5 \mu \mathrm{g})$ was also tested. Antigens were injected intradermally into the upper arm. A positive skintest reaction was defined as $>5 \mathrm{~mm}$ diameter erythema and induration $48 \mathrm{~h}$ after intradermal injection.

\section{Statistical analysis}

The results were analyzed for statistical significance by two-way ANOVA using Prism computer software.

\section{Results}

\section{Generation of dendritic cells}

Dendritic cells were generated from $\mathrm{CD} 14^{+}$progenitor blood monocytes. Phenotypic characteristics of cultured dendritic cells were analyzed by FACS to ascertain quality and purity. After 7 days of culture with GM-CSF and IL-4, dendritic cells differentiated from CD14 ${ }^{+}$ peripheral blood monocytes appeared as non-adherent cells with the typical dendritic cell morphology and high expression of CD1a and HLA class II antigens. Their expression of CD83 and the costimulatory molecules CD80 and CD86 was weaker than that of mature dendritic cells.

As $\mathrm{TNF} \alpha$ upregulates the expression of costimulatory molecules and HLA-DR antigens on dendritic cells (17-19), TNF $\alpha$ was added (day 7) to the culture from cycles four to 12 . TNF $\alpha$ strongly upregulated the expression of CD83, CD80 and CD86 compared with that in immature dendritic cells. Especially with regard to the expression of CD86, dendritic cells treated with TNF $\alpha$ produced a new peak with high fluorescence intensity. The phenotype analysis depicted in Fig. 1 demonstrates that our therapy was based on highquality dendritic cell preparations with purity levels between 80 and $90 \%$.

\section{T-cell proliferative response}

The assessment of immune reactivity of PBMCs was based on the ability to generate tumor-specific reactivity after in vitro exposure of PBMCs to immunizing tumor lysate, KLH and PTH in different concentrations. As seen in Fig. 2, PBMCs exhibited no in vitro reactivity before immunization, against PTH ( $\mathrm{SI}_{\max } 1$ compared with ovalbumin), tumor lysate $\left(\mathrm{SI}_{\max } 1.1\right)$, or $\mathrm{KLH}$ $\left(\mathrm{SI}_{\max }\right.$ 1.3). The unspecific T-cell stimulator, PHA $(100 \mu \mathrm{g} / \mathrm{ml})$, induced a strong in vitro cellular response (SI 281.1).

After six vaccinations (three cycles with immature dendritic cells and three cycles with mature dendritic cells) with tumor lysate-pulsed dendritic cells (but without KLH or PTH), the beginnings of a tumor lysate response, with an SI of $2.3(10 \mu \mathrm{g} / \mathrm{ml})$ to 2.4 $(100 \mu \mathrm{g} / \mathrm{ml})$, could be observed. KLH in high concentrations $(100 \mu \mathrm{g} / \mathrm{ml})$ induced an unspecific response (SI 5.9). In lower concentrations, no reactivity was detectable. For PTH, again, no immune reaction was seen.

As the tumor marker (PTH) increased, we added KLH after the sixth cycle as a tracer antigen to induce a potent $\mathrm{CD} 4{ }^{+}$memory T-cell response. After the first administration, a KLH-specific immunity could be observed (data not shown), which became stronger with continuing treatment. After the 10th vaccination, a strong dose-dependent PBMC response was observed: SI $2.2(1 \mu \mathrm{g} / \mathrm{ml})$ to $13.5(100 \mu \mathrm{g} / \mathrm{ml} ; P<0.003$ 

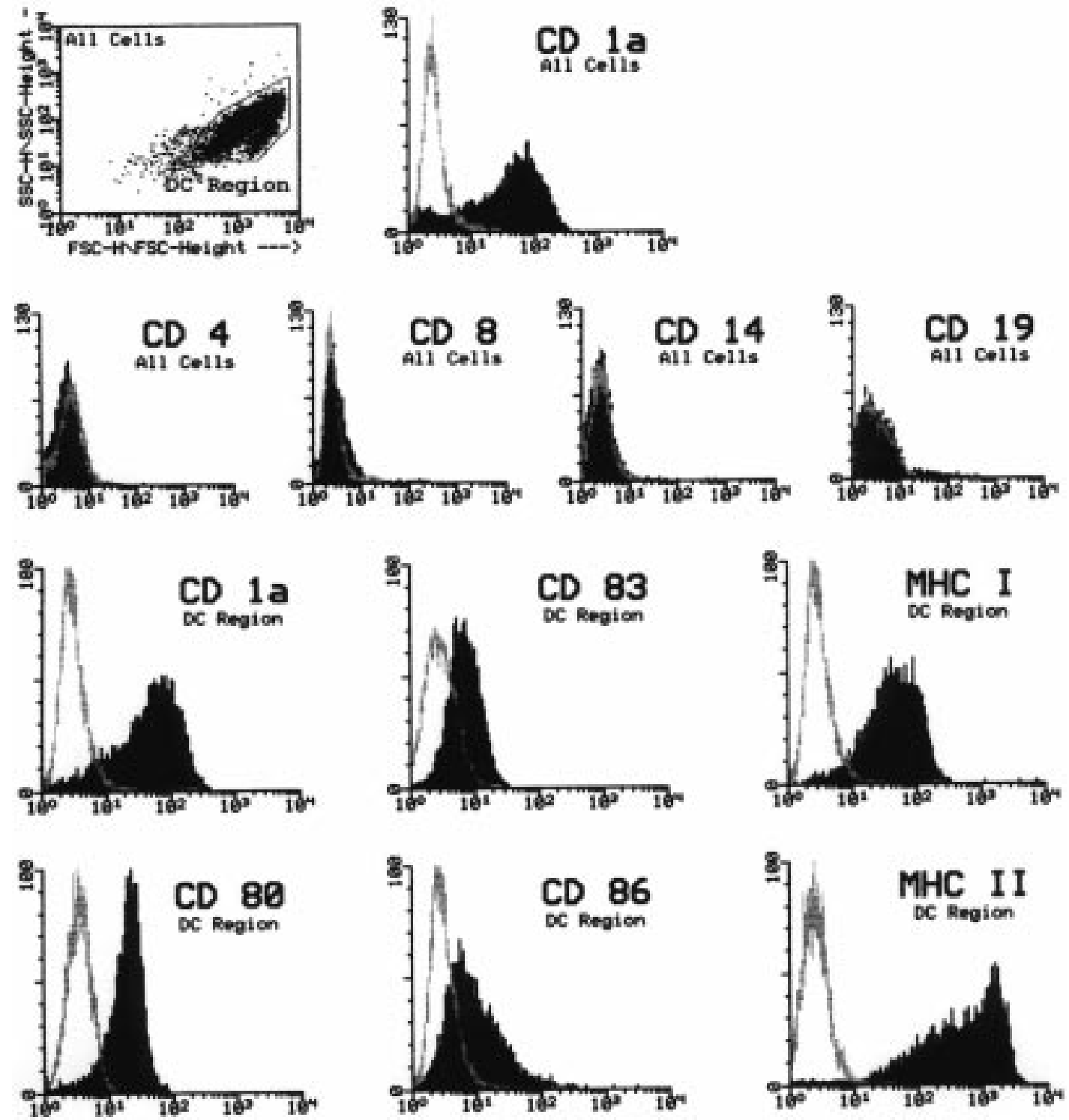

Figure 1 Flow-cytometric analysis of mature dendritic cells at day 7 of culture (culture conditions are given in the text). Dendritic cells strongly expressed CD1a, CD83, CD80, CD86 and HLA class II antigens. T-cells, B-cells and monocytes were excluded by using lineage-associated molecules (CD4, CD8, CD19, CD14). The horizontal and vertical axes represent the fluorescence intensity on a logarithmic scale and the relative cell number on a linear scale, respectively.

compared with pretreatment). We also observed a specific, dose-dependent tumor lysate response: SI 1.8 $(1 \mu \mathrm{g} / \mathrm{ml})$ and $5.7(100 \mu \mathrm{g} / \mathrm{ml}, P<0.003)$. In contrast, a PTH-specific response was still not present, indicating a failure of induction of PTH-specific memory T-cells (SI $\mathrm{max}_{\max }$ 1.1).

\section{Delayed-type hypersensitivity}

To investigate in vivo immune responses, we used the DTH skin reaction as a standard technique for detecting antigen-specific immunity. Before the initial vaccination, we observed no DTH reaction to the antigens tested. Also, after six dendritic cell immunizations (only with tumor lysate), neither an erythema nor an induration was seen. At that time, a tumor lysatespecific in vitro PBMC response was also absent. With the addition of KLH, significant tumor lysate-specific DTH reactivity with erythema and induration $(18 \mathrm{~mm}$ in diameter) was observed (Fig. 3). The DTH response was accompanied by tumor lysate-specific in vitro PBMC proliferation (Fig. 2). Neither an in vitro nor an in vivo response was observed for PTH, suggesting a failure of PTH-specific T-cell immunity. At the same time point, a strong KLH-specific DTH response, with erythema and induration, was present. 


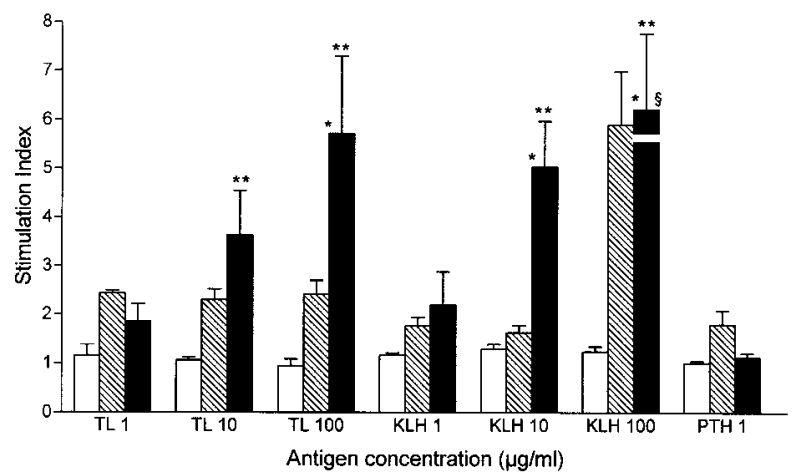

Figure 2 Proliferative responses in $1 \times 10^{5}$ PBMCs co-cultured in vitro with varying concentrations from $1 \mu \mathrm{g} / \mathrm{ml}$ to $100 \mu \mathrm{g} / \mathrm{ml}$ of tumor lysate (TL) or KLH, or PTH ( $1 \mu \mathrm{g} / \mathrm{ml}$ only). Immune response was tested before treatment (open bars), after immunization with tumor lysate (but without $\mathrm{KLH}$; hatched bars) and after KLH administration (black bars). Data are expressed as stimulation indices \pm standard error of mean (S.E.M.). ${ }^{\S} \mathrm{SI}_{\mathrm{KLH} 100}=13.5 ;{ }^{*} P<0.04$ compared with $1 \mu \mathrm{g} / \mathrm{ml} ;{ }^{* *} P<0.003$ compared with pretreatment.

\section{Clinical monitoring}

All vaccinations were well tolerated, with no side effects, and were administered on an outpatient basis. In spite of significant in vitro and in vivo (DTH) immune responses to the antigens, no relevant clinical improvement was achieved. As illustrated in Fig. 4, serum PTH initially increased, then fluctuated between $295 \mathrm{pg} / \mathrm{ml}$ and $523 \mathrm{pg} / \mathrm{ml}$ (cycles 7-12). Serum calcium increased from $2.5 \mathrm{mmol} / \mathrm{l}$ to $3.3 \mathrm{mmol} / \mathrm{l}$. After 12 cycles of immunization, spiral-computed tomography scans of the thorax revealed a progression of lung metastases.

\section{Discussion}

Parathyroid carcinoma is a rare malignancy presenting symptoms of hypercalcemia as a result of increased concentrations of PTH. The 5-year survival rate is estimated to be about 30\% and the 10-year survival rate is around $15 \%$ (20). Radiation and systemic chemotherapy have been unsuccessful in controlling recurrences and metastatic lesions (20-22). We therefore tested the effects of dendritic cell tumor immunotherapy as described here in an attempt to control the growth of our patient's tumor.

This is the first report of tumor vaccination with antigen-pulsed dendritic cells for the treatment of an endocrine carcinoma. By repeated immunization with tumor lysate and KLH, we were able to induce a tumor-specific T-cell response. Most strikingly, we also observed an in vivo immune response, suggesting that the procedure described here is sufficient to induce antitumor reaction against an endocrine carcinoma in humans. In contrast to other in vivo applications, we took advantage of improved and more effectively standardized conditions in culturing the dendritic

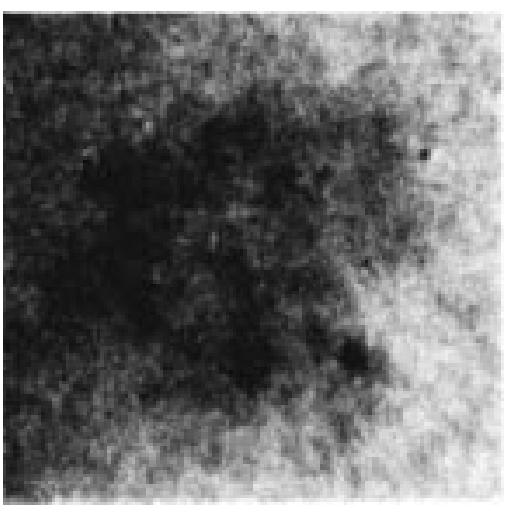

Figure 3 In vivo T-lymphocyte reactivity to tumor lysate. DTH skin reaction $48 \mathrm{~h}$ after administration of tumor lysate $(5 \mu \mathrm{g})$ (shown at cycle 10).

cells, and used immature dendritic cells for exposing to tumor antigens in the process of maturation (23). Mature dendritic cells develop high levels of costimulatory molecules (B7-1 and B7-2) and other characteristic surface markers such as CD1a and CD83. The exposure of dendritic cells activated in vitro to high concentrations of tumor antigen during the maturation process may explain why the ex vivo loading of these cells with antigen is effective in stimulating an immune response, whereas the presence of in vivo tumor is not.

In contrast to other studies in which a variety of shared tumor-associated antigens were used, our procedure proposes tumor lysate for pulsing dendritic cells. A first report using dendritic cells for immunization in humans described the intravenous application of autologous dendritic cells pulsed with idiotypical proteins in four patients with follicular lymphoma, three of whom responded to treatment (23). Another trial of dendritic cell tumor vaccination in advanced prostate carcinomas used a clearly identified tumor antigen (prostate specific membrane antigen) and $27 \%$ of the patients responded to treatment (Phase II trial) (15). Nestle et al. (14) demonstrated an antitumor response in patients with metastasized melanoma, using tumor-associated

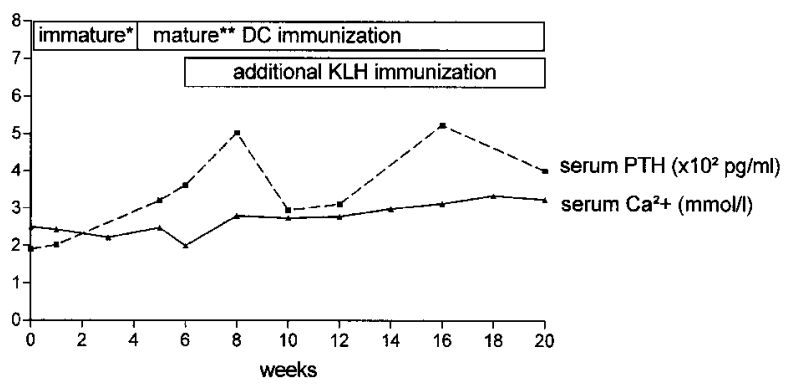

Figure 4 Dendritic cell (DC) immunization schedule, and clinical monitoring of serum PTH and calcium. Immunizations were performed weekly* and at 2 -week ${ }^{* *}$ intervals. 
antigens in addition to tumor lysate. Two of four patients treated with tumor lysate responded to vaccination with partial regression of metastatic nodules. In agreement with our results, this demonstrates that a significant tumor-specific response can also be achieved without the use of defined tumor antigens.

In the present study, a significant in vitro response was not seen when dendritic cells were pulsed with tumor lysate alone. Therefore, we used the highly immunogenic neo-antigen, KLH, for immune stimulation. Previous studies have demonstrated the involvement of $\mathrm{CD}^{+}$cytotoxic and $\mathrm{CD}^{+}$helper T-cells in the induction of effective antitumor immunity $(1,2)$. The use of KLH may therefore be crucial, as it induces a strong T-helper cell response and activates the production of cytokines in the microenvironment of the lymph node, which is necessary for the generation of an effective cytotoxic T-cell response. For any new dendritic cell-dependent tumor immunotherapy, a general application of KLH or a similar immune stimulator should be considered.

Recently, Bradwell \& Harvey (24) have described an alternative approach of tumor immunotherapy in a similar case of metastatic parathyroid carcinoma with severe bone disease and extreme hypercalcemia. The authors used whole PTH (AS 1-84, $50 \mu \mathrm{g}$ ) and different human and bovine PTH peptides $(200 \mu \mathrm{g})$ in combination with complete Freund's adjuvant, administered subcutaneously in intervals of 3-7 weeks. Using this immunization strategy, they were able to break B-cell tolerance. The clinical improvement of the patient was a result of antibody binding to $\mathrm{PTH}$ and inhibiting its uptake by receptors. In contrast to our data, PTHspecific $\mathrm{T}_{\mathrm{H} 2}$-like immune reactivity was demonstrated. This might be explained either by the different method of antigen delivery, possibly resulting in a distinct antigen presentation, or by the lower amount of PTH used in our procedure.

The method of choice for vaccination to induce a specific CTL response in vivo is currently much debated, and no consensus has been reached about the optimal strategy. Both vaccination strategies, subcutaneous and intralymphatical deliveries induced sufficient in vitro and in vivo responses. Hsu et al. (23) demonstrated a high effectiveness of intravenous injections. As primary immune responses are generated in professional lymphoid organs, it is now generally accepted practice to immunize into, or in close proximity to, the lymphatic system. Injecting dendritic cells in a peripheral tissue site may lead to a substantial loss of dendritic cells during migration into the spleen and lymph nodes. Because of this unsolved problem, we decided to divide each dendritic cell preparation into two equal parts and administered them simultaneously by subcutaneous and intralymphatic injections in close proximity to the lymph nodes.

Our data indicate that enriched dendritic cells can be cultured, pulsed with tumor protein, and infused repeatedly into humans without any significant side effects. Relatively small numbers of antigen-pulsed dendritic cells are effective in stimulating an in vitro and in vivo immune response after some treatments. The powerful immune reaction induced with our procedure was, however, correlated with a poor clinical effect. This discrepancy may reflect the advanced stage of the patient's disease, with high tumor masses, the, as yet undefined, tumor antigens in the parathyroid carcinoma, or a failure of specific cytotoxic T-cells even after induction of memory T-cells. Nevertheless, antigen-pulsed dendritic cells represent a powerful new strategy capable of inducing a T-cell immune response against weak antigens such as tumor proteins. Regardless of the clinical outcome of our patient, this approach might be generally applicable to other advanced, radioand chemotherapy-resistant endocrine malignancies, such as adrenal carcinomas and metastasized medullary and anaplastic thyroid carcinomas.

\section{Acknowledgements}

We thank Dr Dirk Schadendorf, from the Clinical Cooperation Unit for Dermato-oncology at the Klinikum Mannheim, University of Heidelberg, for his generous advice.

\section{References}

1 Ellenhorn JD, Schreiber H \& Bluestone JA. Mechanism of tumor rejection in anti-CD3 monoclonal antibody-treated mice. Journal of Immunology 1990144 2840-2846.

2 Cavallo F, Giovarelli M, Gulino A, Vacca A, Stoppacciaro A, Modesti A \& Forni G. Role of neutrophils and CD $4^{+}$T lymphocytes in the primary and memory response to nonimmunogenic murine mammary adenocarcinoma made immunogenic by IL-2 gene. Journal of Immunology 1992149 3627-3635.

3 Huang AY, Golumbek P, Ahmadzadeh M, Jaffee E, Pardoll D \& Levitsky H. Role of bone marrow-derived cells in presenting MHC class I-restricted tumor antigens. Science 1994264 961-965.

4 Cayeux S, Richter G, Becker C, Beck C, Aicher A, Pezzutto A, Dorken B \& Blankenstein T. Lack of correlation between rejection of tumor cells co-expressing interleukin-2 and B7.1 and vaccine efficiency. European Journal of Immunology 199727 1657-1662.

5 Ashwell JD. Are B lymphocytes the principal antigen-presenting cells in vivo? Journal of Immunology 1990140 3697-3700.

6 Oin Z, Richter G, Schuler T, Ibe S, Cao X \& Blankenstein T. B cells inhibit induction of $\mathrm{T}$ cell-dependent tumor immunity. Nature Medicine 19984 627-630.

7 Steinman RM. The dendritic cell system and its role in immunogenicity. Annual Review of Immunology 19919 271-296.

8 Inaba K, Pack M, Inaba M, Sakuta H, Isdell F \& Steinman RM. High levels of a major histocompatibility complex II-self peptide complex on dendritic cells from the T cell areas of lymph nodes. Journal of Experimental Medicine 1997186 665-672.

9 Caux C, Vanbervliet B, Massacrier C, Azuma M, Okumura K, Lanier LL \& Banchereau J. B70/B7-2 is identical to CD86 and is the major functional ligand for CD28 expressed on human dendritic cells. Journal of Experimental Medicine 1994180 1841-1847.

10 Inaba K, Witmer PM, Inaba M, Hathcock KS, Sakuta H, Azuma M, Yagita H, Okumura K, Linsley PS \& Ikehara S. The tissue distribution of the B7-2 costimulator in mice: abundant 
expression on dendritic cells in situ and during maturation in vitro. Journal of Experimental Medicine 1994180 1849-1860.

11 Takahashi H, Nakagawa Y, Yokomuro K \& Berzofsky JA. Induction of $\mathrm{CD}^{+}$cytotoxic $\mathrm{T}$ lymphocytes by immunization with syngeneic irradiated HIV-1 envelope derived peptide-pulsed dendritic cells. International Immunology 19935 849-857.

12 Ashley DM, Faiola B, Nair S, Hale LP, Bigner DD \& Gilboa E. Bone marrow-generated dendritic cells pulsed with tumor extracts or tumor RNA induce antitumor immunity against central nervous system tumors. Journal of Experimental Medicine $19971861177-1182$.

13 Specht JM, Wang G, Do MT, Lam JS, Royal RE, Reeves ME, Rosenberg SA \& Hwu P. Dendritic cells retrovirally transduced with a model antigen gene are therapeutically effective against established pulmonary metastases. Journal of Experimental Medicine 1997186 1213-1221.

14 Nestle FO, Alijagic S, Gilliet M, Sun Y, Grabbe S, Dummer R, Burg G \& Schadendorf D. Vaccination of melanoma patients with peptide- or tumor lysate-pulsed dendritic cells. Nature Medicine 19984 328-332.

15 Tjoa BA, Simmons SJ, Bowes VA, Ragde H, Rogers M, Elgamal A. Kenny KM, Cobb OE, Ireton RC, Troychak MJ, Salgaller ML, Boynton AL \& Murphy GP. Evaluation of phase I/II clinica trials in prostate cancer with dendritic cells and PSMA peptides. Prostate $19983639-44$.

16 Romani N, Gruner S, Brang D, Kampgen E, Lenz A, Trockenbacher B, Konwalinka G, Fritsch PO, Steinman RM \& Schuler G. Proliferating dendritic cell progenitors in human blood. Journal of Experimental Medicine 1994180 83-93.

17 Sallusto F \& Lanzavecchia A. Efficient presentation of soluble antigen by cultured human dendritic cells is maintained by granulocyte/macrophage colony-stimulating factor plus interleukin 4 and downregulated by tumor necrosis factor alpha. Journal of Experimental Medicine 1994179 1109-1118.

18 Alijagic S, Moller P, Artuc M, Jurgovsky K, Czarnetzki BM \& Schadendorf D. Dendritic cells generated from peripheral blood transfected with human tyrosinase induce specific $\mathrm{T}$ cell activation. European Journal of Immunology 199525 3100-3107.

19 Ludewig B, Graf D, Gelderblom HR, Becker Y, Kroczek RA \& Pauli G. Spontaneous apoptosis of dendritic cells is efficiently inhibited by TRAP (CD40-ligand) and TNF-alpha, but strongly enhanced by interleukin-10. European Journal of Immunology 199525 1943-1950.

20 Shane E \& Bilezikian JP. Parathyroid carcinoma: a review of 62 patients. Endocrine Review $19823218-226$.

21 Bukowski RM, Sheeler L, Cunningham J \& Esselstyn C. Successful combination chemotherapy for metastatic parathyroid carcinoma. Archives of Internal Medicine 1984144 399-400.

22 Calandra DB, Chejfec G, Foy BK, Lawrence AM \& Paloyan E. Parathyroid carcinoma: biochemical and pathologic response to DTIC. Surgery 198496 1132-1137.

23 Hsu FJ, Benike C, Fagnoni F, Liles TM, Czerwinski D, Taidi B, Engleman EG \& Levy R. Vaccination of patients with B-cell lymphoma using autologous antigen-pulsed dendritic cells. Nature Medicine 19962 52-58.

24 Bradwell AR \& Harvey TC. Control of hypercalcaemia of parathyroid carcinoma by immunisation. Lancet 1999353 370-373.

Received 9 July 1999

Accepted 18 November 1999 